\title{
Conservation training of three cerebral palsied children
}

\author{
LAWRENCE S. MEYERS, COLETTE L. COLEMAN, and LYNN M. MORRIS \\ California State University, Sacramento, California 95819
}

\begin{abstract}
Three cerebral palsied children between approximately 6 and 11 years of age participated in conservation training. At the outset of training, these children were performing below age level compared with the normal population. A training procedure emphasizing the verbal rule of conservation and minimizing the motor demands of the task resulted in rapid acquisition of trained tasks and generalized mastery of two nontrained conservation tasks. Both trained and generalized mastery were retained over the longest tested interval of 9 weeks. It was suggested that conservation can be acquired and retained with little motor involvement in the original learning.
\end{abstract}

Able-bodied children's performance in conservation tasks and the development of skills mediating such performance have been extensively discussed (e.g., Bruner, 1964; Elkind, 1969; Piaget, 1966). Populations identified with particular disabilities, such as mental retardation, hearing impairment, visual impairment, and cerebral palsy, have also been studied (Brekke, Johnson, \& Williams, 1975; Field, 1974; Furth, 1964; Miller, 1969). Generally, disabled populations tend to demonstrate conservation skills that are delayed with respect to the able-bodied population.

Of these disabled populations, a segment of the cerebral palsied population has such severe motor impairments that the individuals cannot physically interact with their environment in an effective manner. This limits the scope of knowledge they tend to acquire to that which they can directly observe or which they are directly taught. Assuming that motor experience is requisite to the development of conservations skills (Piaget, 1966), this group would then be expected to demonstrate some performance deficiencies.

At issue in the present study is whether severely motor-impaired cerebral palsied children can acquire conservation concepts despite their limited sensorimotor abilities. If motor participation in a task is not a necessary condition to learning conservation concepts, then a training procedure designed to take into account the children's physical limitations might be successful in improving conservation performance. This study reports such an attempt with three nonspeaking cerebral palsied children.

This study is based on a master's thesis of the third author. The authors wish to thank the administrators, teachers, and staff of Bowling Green Elementary School for their support and cooperation. Reprint requests should be sent to Lawrence S. Meyers, Department of Psychology, California State University, Sacramento, California 95819.

\section{METHOD}

\section{Subjects}

Three severely physically disabled cerebral palsied children from Bowling Green Elementary School in the Sacramento City Unified School District served as subjects. Subject A, a female, was 11 years 5 months old (11-5) at the start of the study; Subject B, a female, was 9-3; Subject C, a male, was 6-1. Each was nonspeaking but had some means of communicating "yesno," could hear within normal limits, and understood the "same-different" concept. In addition, none had yet acquired all of the skills of conserving number, length, mass, weight, and volume.

\section{Materials}

A wide-range battery of conservation tests was administered to subjects several times in the study, making use of the same materials. Ten bottle tops were used to test conservation of number, and length was tested with two 12 -in. wooden rulers. Conservation of mass was determined with two $6-\mathrm{oz}$ balls of Play Dough. Two different beakers and colored water were used to assess conservation of volume. Weight was tested with a balance scale and $6 \mathrm{oz}$ of Play Dough. Training in conservation tasks occurring between administrations of the wide-range battery made use of a large variety of commonly available materials, such as paper clips, beans, pens, rubber bands, socks, ribbons, stamps, and yarn.

\section{Procedure}

General. Subjects were tested and trained individually twice weekly for approximately $30 \mathrm{~min}$ in a small room. Time constraints of the school setting necessitated training the three subjects in succession; that is, all training of one subject was completed prior to the training of the next subject. To procedurally control for maturational/educational changes that might have occurred because of this, a constant wide-range battery of conservation tests was administered to all subjects on each of 5 days at prescribed stages of the study. Specifically, all subjects received this battery on Day 1 of the study. Training for Subject A was then begun. When Subject A reached learning criterion on the trained conservation tasks, all subjects once again received, on the same day, the wide-range battery. This same procedure was continued for the remaining two subjects. Five weeks after the last subject was tested, a final administration of the wide-range battery was administered. No training took place during these last 5 weeks. Thus, the procedure involved the fol- 
lowing steps: an initial administration of the wide-range battery, training on certain conservation tasks, criterion testing on those tasks, and subsequent administration of the wide-range battery.

Wide-range battery testing. Objects were arranged to make it obvious that they were equal. Each transformation was always carried out in full view of the subject. The conservation question was of the form: "Are [is] there the same [number, amount, etc.] now? Does one [row, object] have more?" If the subject indicated that the two were different, it was determined which of the two alternatives had more. If the subject indicated no difference, the next trial was presented. No feedback regarding the correctness of the judgment was given.

The wide-range battery consisted of a single test trial for each of the conservation concepts. These concepts were number, length, mass, weight, and volume. They were always administered in the order listed above.

Training. Each session involved training on each of the first two tasks failed on the wide-range battery. The two concepts were trained successively in a single session for 13 trials each (10 conservation and 3 nonconservation transformations) and followed the procedures described below for criterion testing. Training differed from testing only in the form of feedback provided to the child. For incorrect or inadequate responses, the verbal rule underlying the transformation was explained in the manner detailed by Beilin (1965). For correct responses, the underlying rule was also repeated, as described by Field (1974).

Criterion testing. The effects of training were tested using the same mode as the wide-range battery but involved only those two conservation tasks included in the training. Criterion testing was given on the day following each training day. Thirteen trials per concept were administered during the criterion testing. Of the 13 trials, 10 transformations created equal alternatives (conservation) and 3 created unequal alternatives (nonconservation); these trial types were distributed randomly in the set. Mastery criterion was 9 of 10 correct conservation judgments; nonconservation trials were not used as part of the mastery criterion.

\section{RESULTS}

The results of this study are presented in Table 1. On the first administration of the wide-range battery of conservation tests, only Subject A demonstrated some success; she solved both the number and length tasks. Training was therefore given on the conservation tasks of mass and volume. The criterion test for this subject indicated that the 1 training day brought her up to a mastery level. ${ }^{1}$ On the second administration of the widerange battery, this subject not only retained mastery of the two trained tasks but also solved the remaining problem of weight. This mastery was maintained over the remaining weeks of the study.

Subject B consistently failed all problems on the first two administrations of the wide-range battery. Following 2 training days on conservation of number and length, she solved both those problems and generalized to conservation of mass. She, too, retained mastery of these skills over the remainder of the study.

Subject C consistently failed all problems on the wide-range battery for three administrations subsuming a 3 -week period. Following training on the number and length tasks, another administration of the wide-range battery was given. He not only solved the two problems on which he was trained but successfully generalized to the mass and volume problems as well. On the final administration of the wide-range battery, he continued to solve the number and length tasks but demonstrated generalization only on the mass problem.

Table 1

Performance on the Wide-Range Battery, Training, and Percentage Correct on Criterion Tests for Three Subjects on Conservation Tasks

\begin{tabular}{|c|c|c|c|c|c|c|c|c|c|c|c|c|c|c|c|c|}
\hline \multirow[b]{2}{*}{ Procedure } & \multirow[b]{2}{*}{ Day } & \multicolumn{5}{|c|}{ Subject A } & \multicolumn{5}{|c|}{ Subject B } & \multicolumn{5}{|c|}{ Subject C } \\
\hline & & $\mathrm{N}$ & $\mathrm{L}$ & $\mathbf{M}$ & V & W & $\mathbf{N}$ & $\mathbf{L}$ & $\mathbf{M}$ & V & W & $\mathbf{N}$ & L & $\mathbf{M}$ & $\mathbf{V}$ & W \\
\hline & \multicolumn{16}{|c|}{ Week 1} \\
\hline $\begin{array}{l}\text { Wide-Range Battery } \\
\text { Training }\end{array}$ & $\begin{array}{l}1 \\
6\end{array}$ & + & + & $\bar{*}$ & $\bar{*}$ & - & - & - & - & - & - & - & - & - & - & - \\
\hline & \multicolumn{16}{|c|}{ Week 2} \\
\hline & 8 & & & 100 & 90 & & & & & & & & & & & \\
\hline Wide-Range Battery & 8 & + & + & + & + & + & - & - & - & - & - & - & - & - & - & - \\
\hline $\begin{array}{l}\text { Training } \\
\text { Criterion Testing } \\
\text { Training }\end{array}$ & $\begin{array}{l}13 \\
15 \\
20\end{array}$ & & & & & & $\begin{array}{c}* \\
80\end{array}$ & $\begin{array}{l}\text { eek } \\
* \\
80\end{array}$ & & & & & & & & \\
\hline Training & \multicolumn{16}{|c|}{ Week 4} \\
\hline \multirow[t]{2}{*}{$\begin{array}{l}\text { Wide-Range Battery } \\
\text { Training }\end{array}$} & $\begin{array}{l}22 \\
35\end{array}$ & + & + & + & + & + & + & + & + & - & - & $\bar{*}$ & $\bar{*}$ & - & - & - \\
\hline & \multicolumn{16}{|c|}{ Week 5} \\
\hline $\begin{array}{l}\text { Criterion Testing } \\
\text { Wide-Range Battery }\end{array}$ & $\begin{array}{l}37 \\
37\end{array}$ & + & + & + & + & + & + & + & + & - & - & $\begin{array}{c}100 \\
+\end{array}$ & $\begin{array}{c}100 \\
+\end{array}$ & + & + & - \\
\hline & \multicolumn{16}{|c|}{ Week 9} \\
\hline Wide-Range Battery & 72 & + & + & + & + & + & + & + & + & - & - & + & + & + & - & - \\
\hline
\end{tabular}

Note-Conservation tasks: $N=$ number, $L=$ length, $M=$ mass, $V=$ volume, $W=$ weight. “+” = pass, “-” = fail. $"$ "Trained task. 


\section{DISCUSSION}

The results of this study demonstrated that with relatively little formal training, each of these three children made substantial short- and long-term advances in their ability to solve conservation problems. This training involved verbally relating the solution rule to the subjects after they had observed but not participated in the physical manipulation of the test materials. Such observational learning is a prevalent learning method for children such as these, since their severe motor disability has restricted their range and amount of sensorimotor experience compared with that of able-bodied children. Their familiarity with this type of learning may be one reason why each child demonstrated mastery and long-term retention of one additional, nontrained conservation concept.

Although composing a very small sample, these subjects represent a profile shared by other cerebral palsied children: Each showed initial conservation performance below the norms established for able-bodied children. Each produced a score on Dunn's (1965) Peabody Picture Vocabulary Test (PPVT) that, if transformed to the norms standarized on the able-bodied population, would have yielded performance between 1 and 3 years over age level. Each was severely motor impaired, nonverbal, and functioning below grade level in reading, arithmetic, and other academic skills.

It is apparent that these children's academic performance varies. Some tasks appear to require minimal motor skills (e.g., receptive language as tested by the PPVT) in order to develop. These children showed above age-level abilities in such tasks. Other tasks may require more active motor participation (e.g., manipulation of objects and writing for mathematics) in order for the underlying skills to develop. The children demonstrated skills below grade level on these tasks. The learning of conservation skills has also traditionally been viewed as having a strong motor component (Piaget, 1966). The children in this study did demonstrate conservation skills below age level when initially tested. At issue in the present study was whether it was possible to compensate for deficiencies in motor skills and experience. This issue appears to be solved positively. By using techniques that circumvented the children's motor deficiencies, it was possible to efficiently teach conservation concepts. In fact, this learning generalized to an additional conservation concept.

In such a light, the present results are encouraging and directive. The conservation training used here minimized the motor demands made on the subjects; instead, the to-be-learned material was carried by language and demonstration by the tester. It appears that these subjects possessed the intellectual capabilities to understand and incorporate conservation principles into their knowledge structure. To the extent that the success demonstrated here would apply to other children of similar profile, alternative training methods that do not rely so heavily on motor experience and competence might productively by applied to tasks traditionally believed to require a strong motor component for learning.

\section{REFERENCES}

BEILIN, H. Learning and operational conversence in logical thought development. Journal of Experimental Child Psychology, 1965, 2, 317-339.

Brekke, B., Johnson, L., \& Williams, J. D. Conservation of weights and the motorically handicapped. Journal of Special Education, 1975, 9, 389-393.

Bruner, J. A. The course of cognitive growth. American Psychologist, 1964, 19, 1-15.

Dunn, L. M. Peabody picture vocabulary test. Circle Pines, Minn: American Guidance Services, 1965.

ElKind, D. Conservation and concept formation. In D. Elkind \& J. H. Flavell (Eds.), Studies in cognitive development. New York: Oxford University Press, 1969.

FIELD, D. Long-term effects of conservation training with educationally subnormal children. Journal of Special Education, 1974, 8, 237-245.

FURTH, H. G. Conservation of weight in deaf and hearing impaired children. Child Development, 1964, 35, 143-150.

Mille R, C. K. Conservation in blind children. Education of the Visually Handicapped, 1969, 1, 101-108.

Piaget, J. The child's perception of physical causality. Totowa, N.J: Littlefield, Adams, 1966.

\section{NOTE}

1. For this and the other two subjects, no errors on the nonconservation trials were made during criterion testing.

(Received for publication March 23, 1982.) 